- Unilateral cleft lip and palate (UCLP) patients who had undergone orthodontic treatment in the NHS consultant-led service had a good standard of orthodontic care.

- This means PAR reduction could be used as a benchmark for future audit projects and the annual NHS consultant appraisal process.

- Specific issues such as buccal segment relationships on the cleft side create difficulties for orthodontists during treatment for UCLP patients.

- Some cases (7.5\%) which did not improve suggest that a proportion of UCLP patients are difficult to treat. This may be due to factors such as poor compliance or poor growth during orthodontic treatment.

\title{
What are the occlusal outcomes for unilateral cleft lip and palate patients? A national project in the UK
}

\author{
S. Deacon, ${ }^{1}$ P. Bessant, ${ }^{2}$ J. I. Russell ${ }^{3}$ and I. Hathorn ${ }^{4}$
}

\begin{abstract}
Aim This national project assessed the orthodontic outcome for unilateral cleft lip and palate (UCLP) patients in the UK.

Method Six consecutively treated fixed appliance cases where orthognathic surgery was not undertaken were assessed using the peer assessment rating (PAR) index on orthodontic study models. These cases were submitted by NHS consultant orthodontists undertaking treatment on patients with cleft lip and/or palate.

Setting UK NHS consultant-led hospital service.

Results The mean reduction in PAR score was $69 \% \pm 22$. The mean start PAR score was $41 \pm 11$. The mean end of treatment PAR was $12 \pm 9$. The proportion of cases where the score was worse or no different was $7.5 \%$.

Conclusion The mean percentage PAR reduction compares well with other national projects looking at outcome from patients treated in the hospital service. The mean PAR reduction could be used as a benchmark for outcome in UCLP orthodontic treatments in future audit projects and the annual consultant appraisal process.
\end{abstract}

\section{INTRODUCTION}

Orthodontists have been involved in assessment of surgical outcome for unilateral cleft lip and palate (UCLP) using the GOSLON index ${ }^{1}$ and/or five year index. ${ }^{2}$ These two methods assess early anterior-posterior growth of the jaws of UCLP patients using orthodontic study models. This gives an

\footnotetext{
${ }^{1 *}$ South West Cleft Unit, ${ }^{2}$ Orthodontic and Maxillofacial Laboratory, Frenchay Hospital, Bristol, BS16 1LE; ${ }^{3}$ Cleft Lip \&t Palate Network North West, Isle of Man \&t North Wales, Alder Hey Hospital, Eaton Road, Liverpool, L12 2AP; ${ }^{4}$ South West Cleft Unit, Frenchay Hospital, Bristol, BS16 1LE

${ }^{*}$ Correspondence to: Mr Scott Deacon

Email:scott.deacon@nbt.nhs.uk
}

\section{Online article number E18}

Refereed Paper - accepted 20 March 2007

DOI: $10.1038 /$ bdj.2007.807

${ }^{\circledR}$ British Dental Journal 2007; 203: E18 indication of the effect of the primary surgery required to repair the cleft, on growth of these structures. Despite the enthusiasm to assess these outcomes, ${ }^{3-9}$ little has been published on the occlusal outcomes of orthodontic treatment within this group of cleft lip and palate patients. ${ }^{10}$

A previous national project established a benchmark for assessing occlusal outcome in non-cleft patients. ${ }^{11}$ This included contacting all 204 consultant orthodontists at the time and inviting them to submit six consecutively treated cases debonded after 1 August 1999. A total of 823 cases were assessed using the PAR index. The mean percentage reduction of PAR in this group was 78\%. From this study, the authors recommended a standard for PAR score reduction for cases treated by orthodontic consultants. This standard was that $75 \%$ of cases should exhibit a reduction in PAR score greater than $70 \%$, with fewer than $3 \%$ of cases having a reduction of lower than $30 \%$. It was thought appropriate to use this same model to assess the occlusal outcome for patients with a complete UCLP that did not require surgical correction of the skeletal bases, in the UK.

It was intended that consultant orthodontists involved in the treatment of patients with cleft lip and palate would thus establish a national standard of outcome. It was anticipated that this might be particularly useful for lead clinicians in cleft centres treating large numbers of cleft lip and palate cases. It would allow them to monitor their own outcomes and assess the spoke orthodontist treating small numbers of cases within their departments. Such a standard could also be utilised in the annual consultant appraisal process and would allow for sensible and fair assessment of a consultant's treatment outcome, set against a national standard.

The aim of this project was therefore to assess the standard of orthodontic treatment provided nationally for patients with UCLP. This will set a level of outcome for future audit and consultant appraisal in the orthodontic care of UCLP cases. 
METHOD

Sample

All consultants in the UK involved in the provision of orthodontic treatment for cleft lip and palate cases were contacted and asked to provide pre- and post-treatment study models with the following criteria:

1. Six consecutively treated UCLP cases treated with fixed appliances

2. Appliances had been debonded prior to the submission date and cases were not excluded if the treatment had been stopped early due to poor compliance

3. Patients with UCLP who had undergone orthognathic treatment to correct any skeletal discrepancy were excluded

4. The study models were to be duplicated and anonymised prior to delivery to the scoring centre.

Additional clinical features were recorded from information supplied on a pro-forma sheet by the treating clinician and examination of the study models, by one examiner (SD). This included the following details:

- Confirm diagnosis

- Treatment length

- Number of appointments

- Cleft site

- Record congenital absence of teeth

- Record extraction patterns in each quadrant

- Evidence of space opening or closure in treatment in the incisor region

- Dental centreline position

- Incisor relationship at the end of treatment

- Overjet at the end of treatment

- Molar relationships at the end of treatment.

\section{Assessment}

A calibrated PAR scorer (PB) assessed the models and applied the standard UK weightings to the scores. These were entered onto a Microsoft Excel ${ }^{\mathrm{TM}}$ spreadsheet for analysis. The additional features were entered (SD) into a Microsoft Access ${ }^{\mathrm{TM}}$ database and manipulated in Microsoft Excel $^{\text {TM }}$ to generate the graphical output.

\section{RESULTS}

Nineteen units and one region submitted study models. The total number of cases assessed was 128. Figure 1 shows the number of cases provided by each of the cleft centres in each of the regions.

The overall national mean PAR reduction was $69 \% \pm 22$. Dividing the data by regional cleft centre demonstrates that all regions that supplied a sample were within one standard deviation of this mean value (Table 1). The mean start PAR score was $41 \pm 11$. The mean end of treatment PAR was $12 \pm 9$. The proportion of cases where the score was worse or no different was $7.5 \%$

Table 2 shows the mean treatment times and number of patient visits with the effect of extraction versus non extraction treatment and space opening or space closing mechanics where there is a missing upper lateral incisor in the cleft site. Sixty-five percent of the sample had a centreline discrepancy at the end of treatment. The extent of the centreline

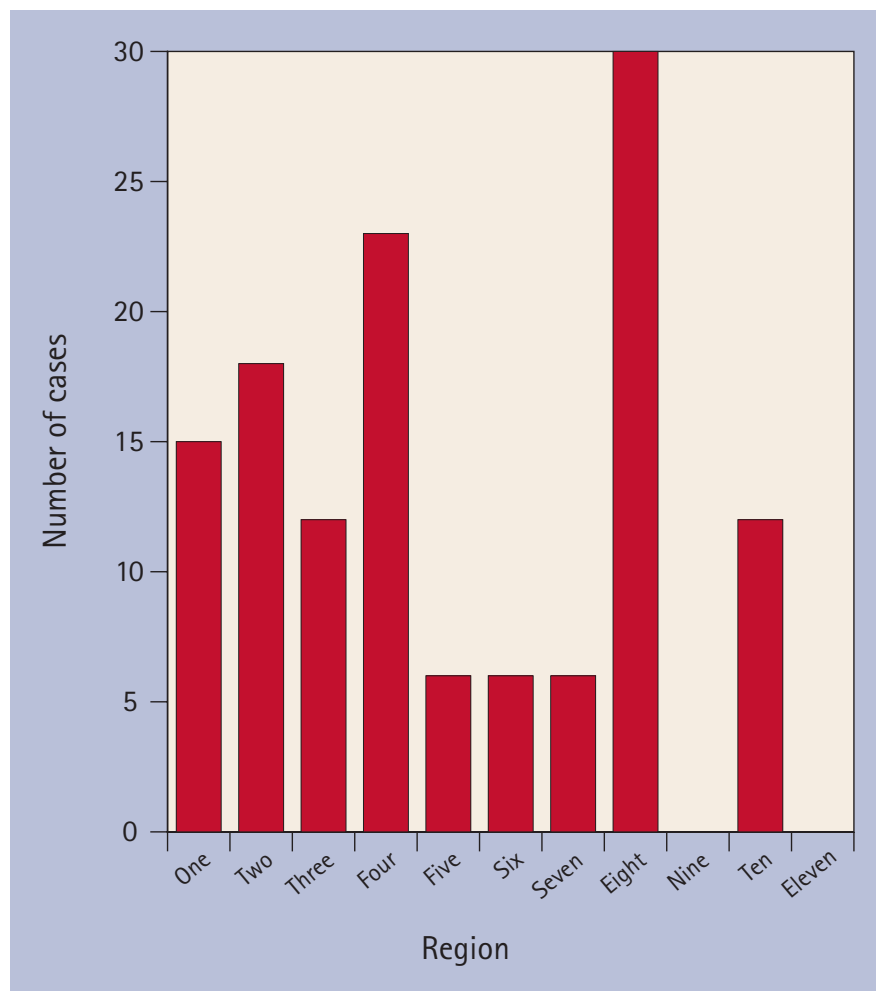

Fig. 1 Number of cases provided by each region

\begin{tabular}{|c|c|c|}
\hline Region & Average PAR reduction & Range of PAR reduction \\
\hline 1 & 60 & $0-90$ \\
\hline 2 & 71 & 20-94 \\
\hline 3 & 76 & $54-96$ \\
\hline 4 & 70 & 3-92 \\
\hline 5 & 69 & $35-86$ \\
\hline 6 & 58 & $11-85$ \\
\hline 7 & 78 & 55-95 \\
\hline 8 & 70 & 29-95 \\
\hline 9 & N/A & N/A \\
\hline 10 & 56 & $22-85$ \\
\hline 11 & $\mathrm{~N} / \mathrm{A}$ & $\mathrm{N} / \mathrm{A}$ \\
\hline
\end{tabular}

\begin{tabular}{|c|c|c|}
\hline & Treatment length & Number of visits \\
\hline Overall & 27 & 18 \\
\hline Extraction treatment & 26 & 18 \\
\hline Non-extraction treatment & 28 & 17 \\
\hline Space opening for upper lateral & 25 & 17 \\
\hline
\end{tabular}

discrepancy when measured on the study models is shown in Figure 2. Missing teeth in the cleft site is common in this cohort of patients and the predominant method for dealing with this orthodontically is space closure, rather than 
opening the space for a prosthetic replacement (Figs 3 and 4). The difficulty in attaining Class I molar relationships at the end of treatment on the cleft side compared to the non-cleft side is shown in Figures 5 and 6.

\section{DISCUSSION}

\section{PAR scores}

The mean pre-treatment PAR score of 41 suggests that on average, the cases were very severe malocclusions. ${ }^{11}$ This figure is higher than the non-cleft cohort treated by consultants in the $\mathrm{UK},{ }^{11}$ where the mean pre-treatment PAR was 33 , and another non-cleft sample from the USA. ${ }^{12}$ The end of treatment PAR of 12 was a figure higher than the non-cleft cohort, with a posttreatment mean PAR score of 7 . The recommendation from the authors of the non-cleft cohort is that 3\% or fewer cases should have PAR reductions in the worse or no different category. The cleft lip and palate cohort had twice the proportion of cases in this category. This suggests that UCLP cases deviate initially by a larger amount from the ideal and therefore may be more difficult to treat to an ideal result.

\section{Treatment length}

Treatment length is variable depending on the orthodontist and the complexity of the case. In this cohort, extraction versus non-extraction and space opening or closing mechanics for missing lateral incisors had little effect on the duration of treatment. The treatment length compares well with other published data on treatment length in non-cleft cohorts. There is, however, great variability in the published data, with treatment times varying from $18-30$ months. ${ }^{12-15}$

\section{Centreline}

Centreline correction is an important factor in the successful outcome of treated orthodontic cases. The UK weightings assign a multiplication factor of 4 to centreline discrepancies greater than $1 / 4$ of lower incisor width. ${ }^{16}$ Sixty-five percent of patients in the cleft lip and palate sample had a centreline discrepancy at the end of treatment. Due to the higher incidence of missing lateral incisors in the cleft site, it may be assumed that the discrepancy would be towards the cleft side. This was not demonstrated: $62 \%$ of cases had a centreline discrepancy with the direction of displacement to the non-cleft side. In terms of mechanics used, space closure might be expected to increase the risk of a centreline discrepancy. This is not reflected in the figures with space closure: 43\% (22) of the cohort with a missing tooth on one side of the arch had no centreline discrepancy. In the space opening cohort with a missing tooth, only $26 \%$ (10) had no centreline discrepancy. These are relatively small numbers, but do suggest that space closure does not increase the risk of centreline discrepancy at the end of treatment.

Figure 2 shows that the majority of the centreline discrepancies were less than or equal to $2 \mathrm{~mm}$ when present. These discrepancies would not score on the PAR index and therefore centreline seems not to have contributed greatly to the final PAR score in the majority of cases.

\section{Molar Relationship}

This can be difficult to correct in UCLP cases due to the transverse and anterior-posterior relationships being affected by

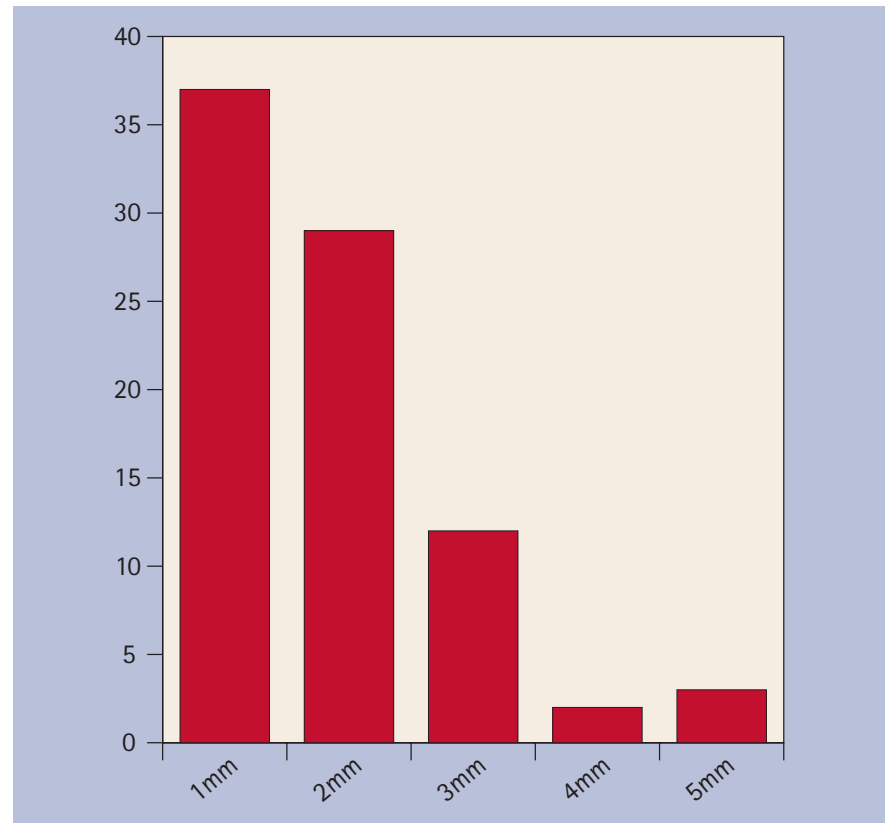

Fig. 2 The size of centreline discrepancy if present

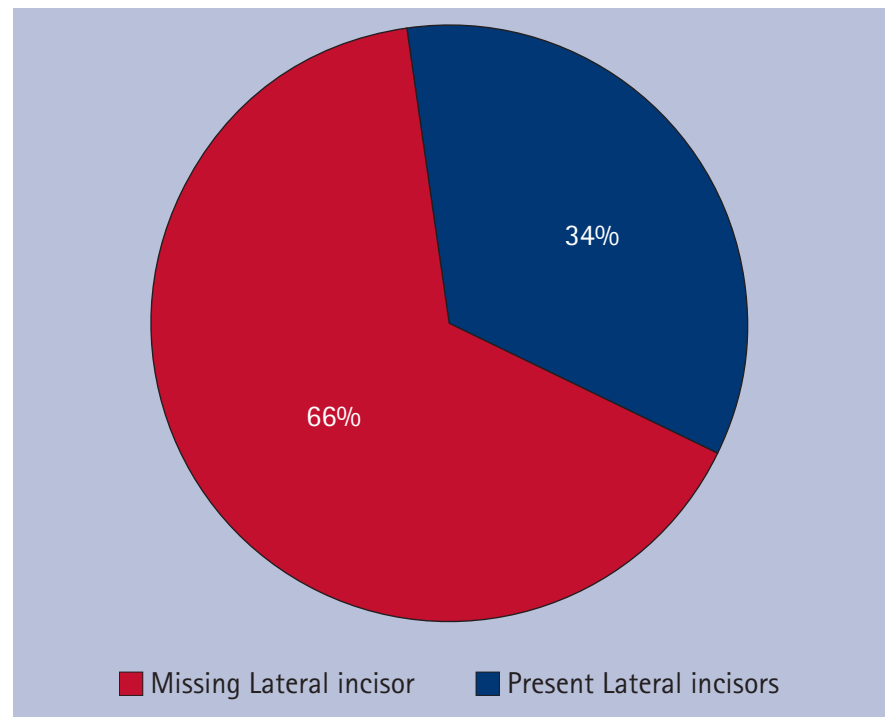

Fig. 3 Proportion of cases with missing upper lateral incisors

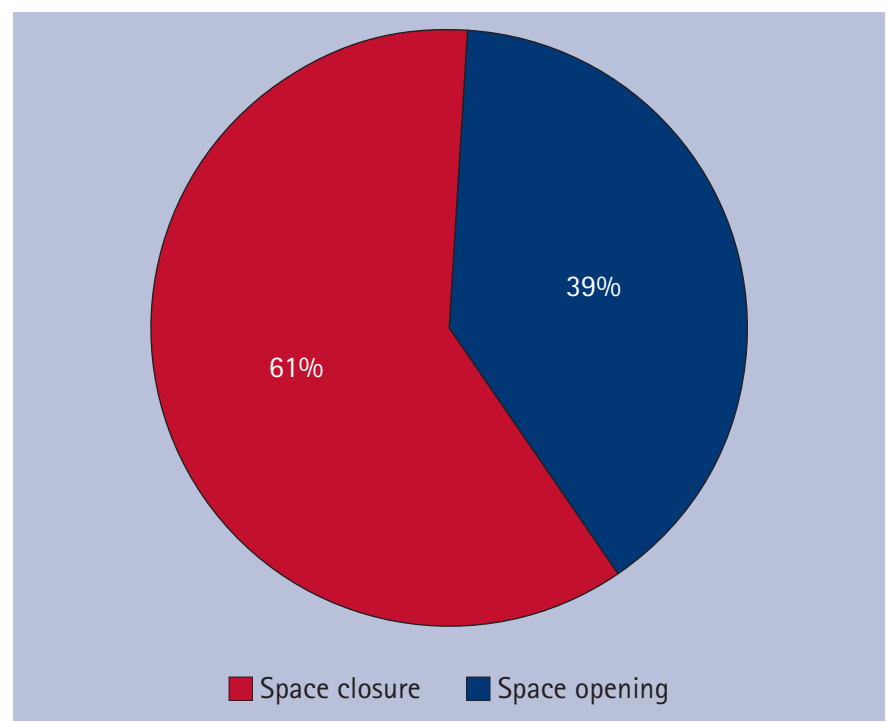

Fig. 4 Proportion of cases with missing lateral incisor with space closing versus opening mechanics 


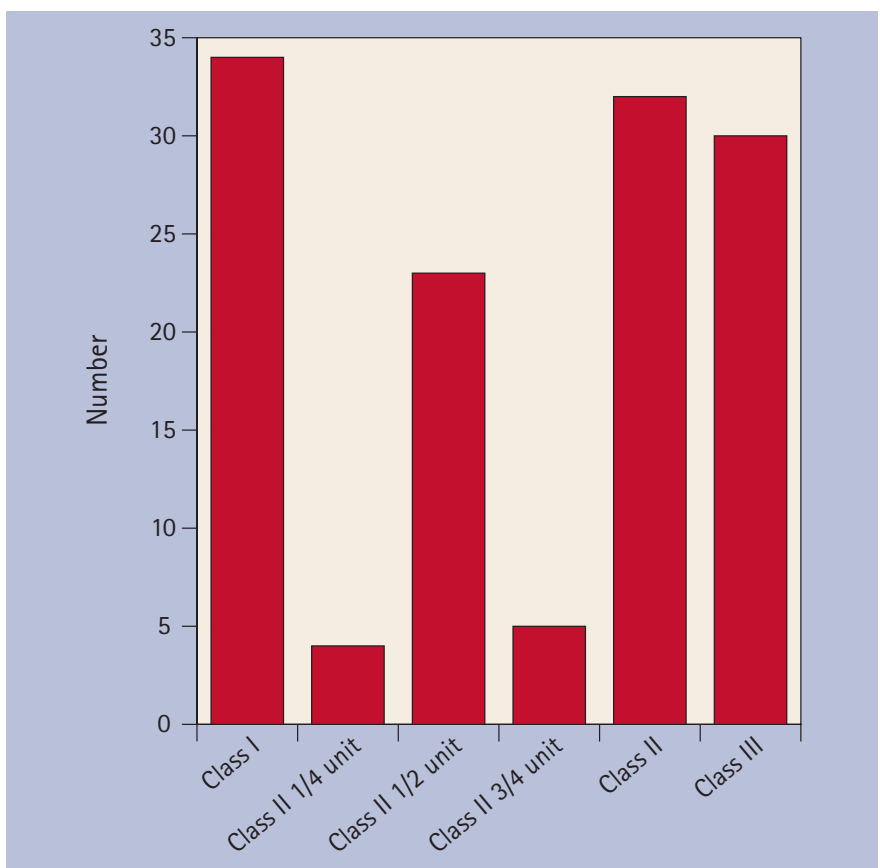

Fig. 5 Molar relationship on the cleft side

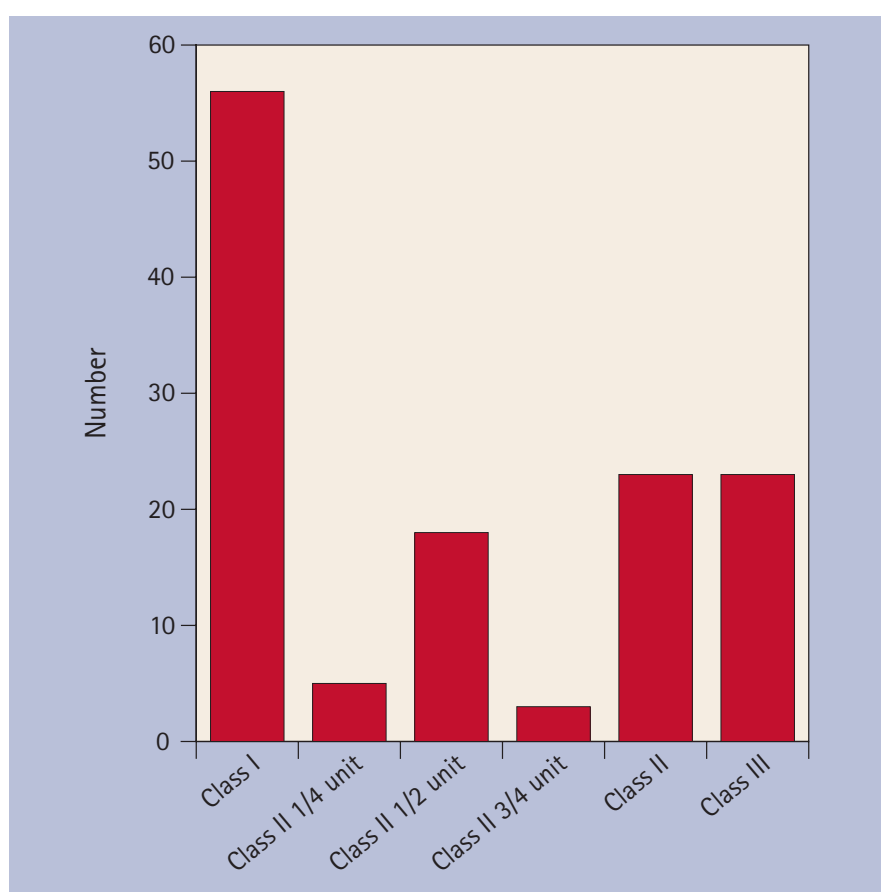

Fig. 6 Molar relationship on the non-cleft side

other factors, such as surgical repair of the cleft and subsequent adverse growth. ${ }^{17,18}$ Figures 5 and 6 suggest that it is more difficult to achieve a Class I molar relationship on the cleft side versus the non-cleft side. This difficulty leads to partial correction of the molar relationship in an anterior-posterior dimension, which contributes substantially to the final PAR score.

\section{Overall PAR reduction}

Overall these are encouraging results, demonstrating the high quality of outcome for patients with UCLP. This is despite other factors which would normally prevent non-cleft patients from being offered active orthodontics. These factors are poor oral hygiene and increased failure to attend. These issues, which not uncommonly affect cleft lip and palate treatments, can affect compliance and in turn outcome.

\section{Weightings}

We applied the UK weightings as developed by Richmond. ${ }^{16}$ This allowed for comparison with a previous project that assessed occlusal outcome in the consultant-based workload in a non-cleft population. ${ }^{11}$ This does have some drawbacks, as an MSc thesis suggests that subjective opinion regarding outcome for UCLP cases is different from that seen in the original PAR weightings study. ${ }^{19}$ Other weightings have been suggested but have not been validated to be used at present. The use of the UK weightings may allow for more direct comparison with outcome in other cohorts. This review of treated cases can be extremely helpful for the consultant appraisal process, which should include some documentation of outcome of orthodontic care related to available national figures.

\section{CONCLUSION}

An overall PAR reduction of $69 \pm 22 \%$ is suggested as a benchmark for the occlusal outcome for fixed appliance therapy in unilateral cleft lip and palate patients.

We would like to thank the British Orthodontic Society for sponsoring this project. We would also like to thank all the individuals who supplied study models for assessment.

1. Mars M, Plint D A, Houston W J, Bergland O, Semb G. The Goslon Yardstick: a new system of assessing dental arch relationships in children with unilateral clefts of the lip and palate. Cleft Palate J 1987; 24: 314-322.

2. Atack N E, Hathorn I S, Semb G, Dowell T, Sandy J R. A new index for assessing surgical outcome in unilateral cleft lip and palate subjects aged five: reproducibility and validity. Cleft Palate Craniofac J 1997; 34: 242-246.

3. Flinn W, Long R E, Garattini G, Semb G. A multicenter outcomes assessment of five-year-old patients with unilateral cleft lip and palate. Cleft Palate Craniofac J 2006; 43: 253-258.

4. Sandy J, Williams A, Mildinhall S et al. The Clinical Standards Advisory Group (CSAG) cleft lip and palate study. Br J Orthod 1998; 25: 21-30.

5. Hathorn I, Roberts-Harry D, Mars M. The Goslon yardstick applied to a consecutive series of patients with unilateral clefts of the lip and palate. Cleft Palate Craniofac J 1996; 33: 494-496.

6. Morris D 0, Roberts-Harry D, Mars M. Dental arch relationships in Yorkshire children with unilateral cleft lip and palate. Cleft Palate Craniofac J 2000; 37: 453-462.

7. Mars $\mathrm{M}$, Asher-McDade $\mathrm{C}$, Brattstrom $\mathrm{V}$ et al. A six-center international study of treatment outcome in patients with clefts of the lip and palate: part 3. Dental arch relationships. Cleft Palate Craniofac J 1992; 29: 405-408.

8. Atack N E, Hathorn I, Dowell T, Sandy J, Semb G, Leach A. Early detection of differences in surgical outcome for cleft lip and palate. Br J Orthod 1998; 25: 181-185.

9. Hathorn I S, Atack N E, Butcher G et al. Centralization of services: standard setting and outcomes. Cleft Palate Craniofac J 2006; 43: 401-405.

10. Subtelny J D, Kyrkanides S. Retrospective revelations: twenty orthodontically treated individuals with unilateral cleft lip and palate. World J Orthod 2004; 5: 152-163.

11. McMullan R E, Doubleday B, Muir J D, Harradine N W, Williams J K. Development of a treatment outcome standard as a result of a clinical audit of the outcome of fixed appliance therapy undertaken by hospital-based consultant orthodontists in the UK. Br Dent J 2003: 194: 81-84.

12. Tulloch J F, Proffit W R, Phillips C. Outcomes in a 2-phase randomized clinical trial of early Class II treatment. Am J Orthod Dentofacial Orthop 2004; 125: 657-667.

13. Popowich K, Nebbe B, Heo G, Glover K E, Major P W. Predictors for Class II treatment duration. Am J Orthod Dentofacial Orthop 2005; 127: 293-300.

14. Faerovig $E$, Zachrisson $B$ U. Effects of mandibular incisor extraction on anterior occlusion in adults with Class III malocclusion and reduced overbite. Am J Orthod Dentofacial Orthop 1999; 115: 113-124.

15. Bishara S E, Cummins D M, Zaher A R. Treatment and posttreatment changes in patients with Class II, Division 1 malocclusion after extraction and nonextraction treatment. Am J Orthod Dentofacial Orthop 1997; 111: 18-27.

16. Richmond S, Shaw W C, O'Brien K D et al. The development of the PAR Index (Peer Assessment Rating): reliability and validity. Eur J Orthod 1992; 14: 125-139.

17. Garrahy A, Millett D T, Ayoub A F. Early assessment of dental arch development in repaired unilateral cleft lip and unilateral cleft lip and palate versus controls. Cleft Palate Craniofac J 2005; 42: 385-391.

18. Semb G. A study of facial growth in patients with bilateral cleft lip and palate treated by the Oslo CLP Team. Cleft Palate Craniofac J 1991; 28: 22-39.

19. Kasem $\mathrm{S}$. Assessing orthodontic treatment in patients with unilateral cleft lip and palate. Manchester: University of Manchester, 2003. Masters Thesis. 